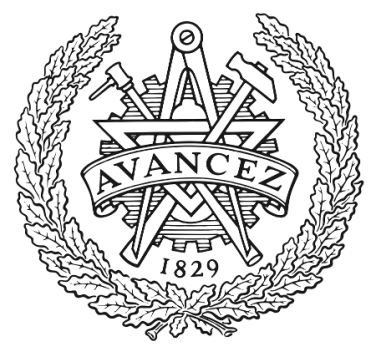

CHALMERS

UNIVERSITY OF TECHNOLOGY

\title{
Force Based Measurement Method for Cooling Flow Quantification
}

Downloaded from: https://research.chalmers.se, 2023-04-26 12:31 UTC

Citation for the original published paper (version of record):

Hobeika, T., Gullberg, P., Sebben, S. et al (2017). Force Based Measurement Method for Cooling Flow Quantification. SAE International Journal of Passenger Cars - Mechanical Systems, 10(2): 619-627. http://dx.doi.org/10.4271/2017-01-1520

N.B. When citing this work, cite the original published paper. 


\title{
Force Based Measurement Method for Cooling Flow Quantification
}

\author{
Teddy Hobeika ${ }^{1}$, Peter Gullberg ${ }^{2}$, Simone Sebben ${ }^{1}$, and Lennart Lofdahl ${ }^{1}$ \\ ${ }^{1}$ Chalmers University of Technology and ${ }^{2}$ Volvo Group Trucks Technology
}

\begin{abstract}
Quantification of heat exchanger performance in its operative environment is in many engineering applications an essential task, and the air flow rate through the heat exchanger core is an important optimizing parameter. This paper explores an alternative method for quantifying the air flow rate through compact heat exchangers positioned in the underhood of a passenger car. Unlike conventional methods, typically relying on measurements of direct flow characteristics at discrete probe locations, the proposed method is based on the use of load-cells for direct measurement of the total force acting on the heat exchanger. The air flow rate is then calculated from the force measurement. A direct comparison with a conventional pressure based method is presented as both methods are applied on a passenger car's radiator tested in a full scale wind tunnel using six different grill configurations. The measured air flow rates are presented and discussed over a wide range of test velocities. The advantages and draw backs of both approaches are compared and discussed in detail. The proposed method is non-intrusive, leaving the heat exchanger core intact, with no need for integration of measurement points over the core region. Due to the measuring principle, the load-cell method will inherently over-predict the air-flow rate. This error is quantified and an empirical correction function is investigated. This paper shows that the corrected force based method determines the air flow rate through a heat exchanger with an accuracy similar to that of traditional pressure/velocity methods while offering a considerable number of advantages.
\end{abstract}

\section{Introduction}

Optimized heat exchangers are an essential part in most engineering systems. Different heat exchangers are commonly used to transfer heat from one coolant, which is typically a fluid running internally through channels, into another coolant, which is normally air flowing externally across the heat exchanger fins. A complicating factor in the optimization process is that in many technical applications, the heat exchangers are positioned in areas of complex flows. One example is the front heat transfer system of road vehicles, where the air flow rate through the compact heat exchanger core is optimized for minimum vehicle drag using both wind tunnel tests and Computational Fluid Dynamics(CFD) simulations. With the introduction of active aerodynamic devices such as grill shutters, this opens up the possibility to have variable control over cooling inlets and thus better control over cooling drag. In addition, modern design cycles require short lead time which calls for fast, accurate and simple methods to determine the air flow rate.

Traditional approaches for quantifying air flow rate through heat exchangers rely on measuring fluid properties such as pressure or velocity. Pressure measurements are commonly conducted using different types of Pitot tubes to determine local pressure drops across the heat exchanger from which the air flow rate can be determined. Alternatively, different types of Prandtl tubes can be used to measure local dynamic pressures, from which the air flow rate can be determined. Different experiments utilizing pressure based methods have been implemented [1-3]. Direct velocity measurements are also used for air flow rate quantifications; hot-wire anemometers or vane anemometers give the local velocities, from which the air flow rate can be computed by integration of local flow velocity. Several experiments exploiting direct velocity measurements have been published $[1,4,5]$. Combined methods have also been presented by Williams and Vemaganti [6] .

These methods can be considered traditional approaches for air flow rate measurements through heat exchangers. These traditional approaches require several local measurement points, hence multiple sensor arrangements positioned on or close to the heat exchanger core are used in order to obtain the velocity distribution over the core. Since there are gaps between the measurement points, integration over the core is required to calculate the air flow rate, this smooths out the velocity distribution and adds uncertainties to the final result. Moreover, heat exchangers are typically positioned in regions where a complex flow situation is prevailing, so external blockage from the equipment together with re-circulation across the core can have a significant influence on the accuracy of all pressure/velocity methods. In general, these methods are known to lack accuracy in low flow velocities and recirculating air flow.

This paper will explore an alternative approach for heat exchanger air flow rate quantification. Using load-cells, the total aerodynamic force acting on the heat exchanger core can be measured, from which total air flow rate can be calculated. This force based approach offers a number of benefits. The method is non-intrusive so the effect of external probe/wiring blockage is eliminated as well as the need for interpolation over the heat exchanger core area. Furthermore the effect of re-circulation and low flow velocities are included in the load-cell measurements, as the total force on the heat exchanger core is measured. To explore the functionality of the method in complex flow fields, this paper applies it to determine the air flow rate through a compact heat exchanger which is mounted in a passenger car vehicle. Also, a traditional pressure based method is applied simultaneously with the force based method, for comparison purposes.

\section{Theory}

In the present approach, the total force acting on the heat exchanger is measured by load-cells located at the heat exchanger mounting points. Isothermal conditions are assumed and all velocities are well below a Mach-number of 0.3 , so the fluid is considered incompressible with a constant density. The core area of the heat exchanger is also constant, so the volumetric flow rates, the mass flow rates, and the average core velocity, following the one-dimensional equation of continuity, are interchangeable variables with only constants separating them as expressed in Equation 1.

$$
\dot{m}_{\text {core }}=\dot{V}_{\text {core }} \times \rho=v_{\text {avg_core }} \times A_{\text {core }} \times \rho
$$


where $\dot{m}_{\text {core }}, \dot{V}_{\text {core }}$, and $v_{\text {avg_core }}$ are, respectively, the mass flow rate, volumetric flow rate, and average velocity all through the core. $A_{\text {core }}$ is the core area and $\rho$ is the air density.

Moreover, the total aerodynamic force acting on the heat exchanger is equal to the product of the average pressure drop across the heat exchanger multiplied by the total surface area of the heat exchanger core, presented in Equation 2.

$$
F_{\text {core }}=\Delta P_{\text {core }} \times A_{\text {core }}
$$

where $F_{\text {core }}$ force acting on the radiator core and $\Delta P_{\text {core }}$ is the pressure drop across the core.

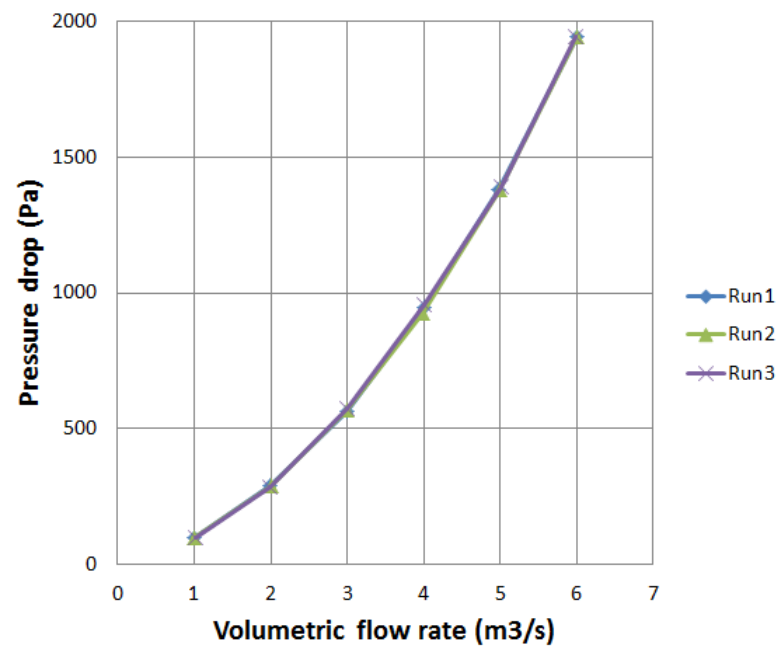

Figure 1: Pressure drop across the heat exchanger core versus volumetric flow rate measured in a plenum-to-plenum test rig over three rest runs.

Figure 1 shows the pressure drop as a function of the volumetric flow rate measured in a plenum-to-plenum test rig at three separate occasions. The repeatability of the pressure characteristics is good. By Equation 1 and Equation 2, it is possible to calculate a relationship between the force acting on the heat exchanger and the average velocity through it. This is shown in Figure 2. One can notice that both curves in Figure 1 and Figure 2 are of second order nature and can be described in equations Equation 3 and Equation 4 respectively, based on the Darcy-Forcheimer law.

$$
\begin{gathered}
\Delta P_{\text {core }}=\left(\frac{1}{2} \rho C_{2}{\frac{\dot{V}_{\text {core }}}{A_{\text {core }}}}^{2}+\frac{1}{\alpha} \mu \frac{\dot{V}_{\text {core }}}{A_{\text {core }}}\right) \times \Delta x \\
F_{\text {core }}=\left(\frac{1}{2} \rho C_{2} v_{\text {avg_core }}^{2}+\frac{1}{\alpha} \mu v_{\text {avg_core }}\right) \times A_{\text {core }} \times \Delta x
\end{gathered}
$$

where $C_{2}$ is the inertial resistance coefficient and $\frac{1}{\alpha}$ is the viscous resistance coefficient through the heat exchanger core. These coefficients are both empirically obtained, $\Delta x$ is the width of the heat exchanger core, $\mu$ and $\rho$ are the air dynamic viscosity and density.

The principle idea behind the force based air flow method is to measure the total forces acting on the heat exchanger core and calculate the air flow rate using Equation 4. Since it has been shown by Henriksson [7] that the pressure drop to average velocity characteristic of the heat exchanger is valid for various flow conditions, including non-perpendicular oncoming air flow, the force to average velocity curve in Figure 2 can be used in complex flow fields.

One challenge in the prediction of air flow rate using load-cells is linked to the fact that the relationship between the force on the heat exchanger and the air flow rate through it is described by a quadratic polynomial. Due to the non-uniform flow, the average force acting on the heat exchanger will over-predict the average core velocity, a quantification

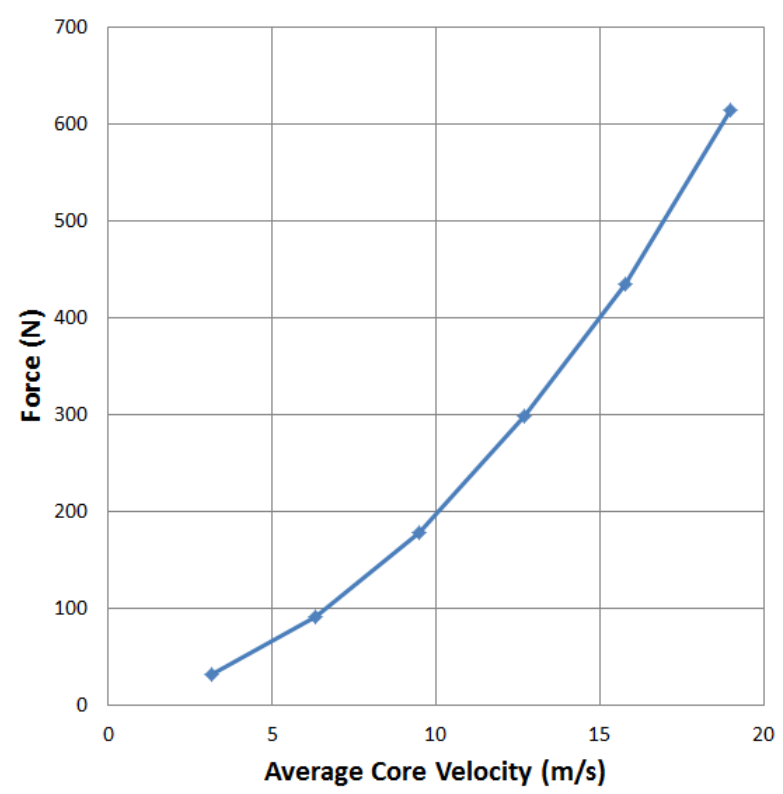

Figure 2: Calculated force versus average core velocity.

of this over prediction and correction for this must be included in the method.

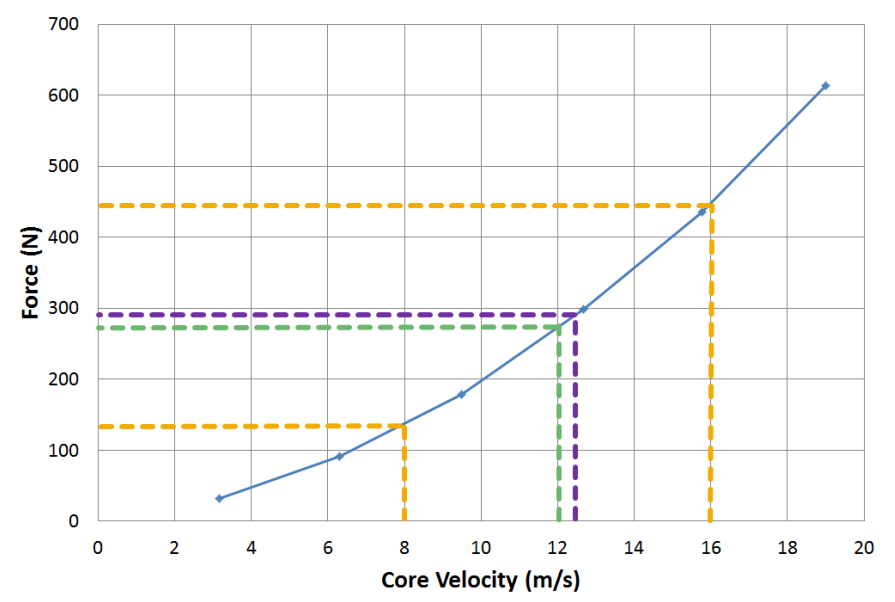

Figure 3: Over prediction demonstration on force versus velocity curve.

A simple example of such a typical over prediction is shown in Figure 3. Assuming that half of a heat exchanger is subjected to a core velocity of $8 \mathrm{~m} / \mathrm{s}$ and the other half to $16 \mathrm{~m} / \mathrm{s}$ (the two local velocities are marked in yellow). This results in an average core velocity of $12 \mathrm{~m} / \mathrm{s}$ (marked in green) and an average total force (marked in purple). As it can be seen, the green and purple lines do not match, thus measuring an average force will not enable a spot on prediction of average core velocity. This is due to the quadratic non-linearity of the pressure characteristic, the force average inherently over-predicts the average core velocity. In this severe non-uniform case it over predicts with $0.5 \mathrm{~m} / \mathrm{s}$, which is equivalent to $4 \%$ higher mass flow.

To evaluate the performance of the force approach and necessary corrections, a traditional pressure based method has been carried out in conjunction with the force based method, thus providing a reference for comparison.

Given the deficit of the force based method, inhomogeneity of flow will be an important parameter of this paper. Inhomogeneity is a measure 
used to describe the deviation of the local velocity measurements from the average velocity through the core. The higher the inhomogeneity, the broader the spread of velocities, and the larger the over prediction will be, as explained in Figure 3.

The equation for calculating inhomogeneity used in this paper is taken from Hucho [8] and presented in Equation 5.

$$
i=\frac{1}{n} \sum_{k=1}^{n} \frac{\left|\dot{m}_{\text {local_k }} \frac{A_{\text {core }}}{A_{\text {local_k }}}-\dot{m}_{\text {core }}\right|}{\dot{m}_{\text {core }}}
$$

where $n$ is the number of measurement points, $\dot{m}_{\text {local } k} k$ is the mass flow through one area section, $A_{\text {local_k }}$ is the size of one area section, $A_{\text {core }}$ is the size of the complete heat exchanger core area, and $\dot{m}_{\text {core }}$ is the total mass flow through the heat exchanger.

\section{Experimental Setup}

Two separate experiments were conducted to be able to quantify the air flow rate. The first experiment is performed in a plenum-to-plenum test rig, for empirical calibration purposes, and the second is performed in an Aerodynamic Wind Tunnel, where the heat exchanger is mounted in its operative environment in a vehicle.

\section{Plenum-to-Plenum rig test}

A closed loop plenum-to-plenum test facility at Volvo Group Truck Technology (Volvo GTT) was used to test the pressure characteristics of the heat exchanger. The test rig is shown in Figure 4. The outlet chamber is kept at atmospheric pressure, and the pressure drop across the test object is measured plenum to plenum, while the air flow rate is measured using six Venturi type nozzles (ISA 1932). To operate the nozzles within their correct Reynolds number range for different mass flows, combinations of open and closed nozzles are used. More information on the Volvo GTT Test Rig can be found in Gullberg [9].

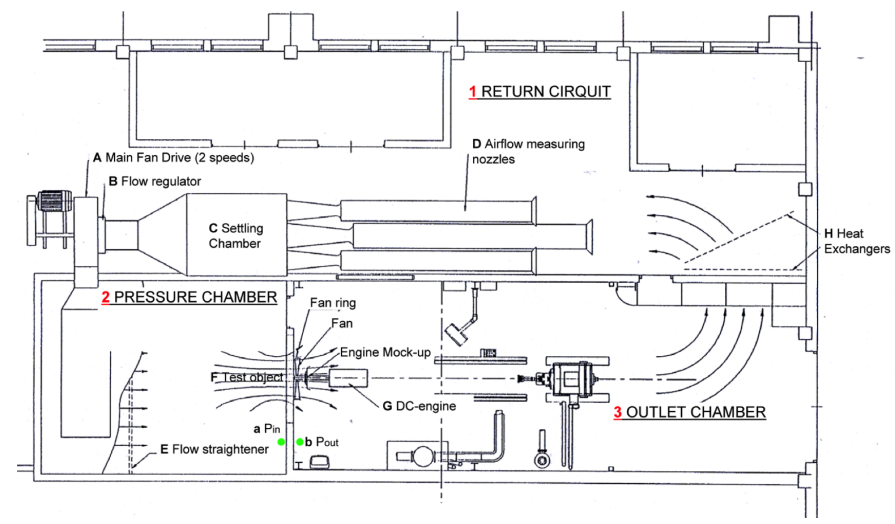

Figure 4: Schematic of the Test Rig at Volvo GTT.

A DTC Initium data acquisition pressure system was used for the local pressure measurements at the heat exchanger core, utilizing two 32 port ESP scanners for the total of 64 pressure measurements. The probes used for these pressure measurements are the so-called Ruijsink micro-probes which are described in Ruijsink [2]. The complete radiator setup is shown in Figure 5. The test in the rig is mainly a calibration test which is performed to calibrate the probe measured velocities to the average velocity through the heat exchanger core. This is needed since the geometrical blockage through the probe is not the same as that through the fins of the heat exchanger. Also the process of mounting the probes can highly influence the blockage each probe creates. In the

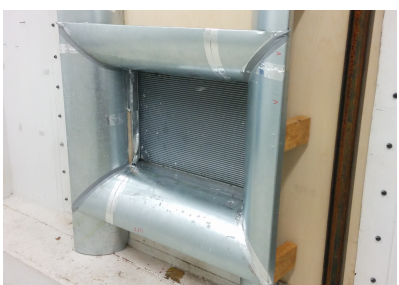

(a) Pressure Chamber

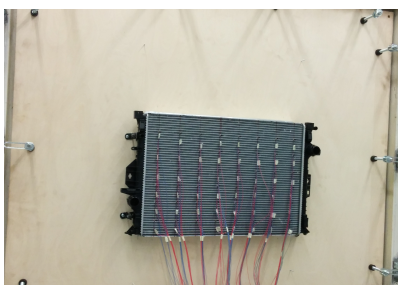

(b) Outlet Chamber
Figure 5: The radiator setup in the test rig.

test rig a calibration test for each probe can be obtained thus almost eliminating errors due to geometrical differences and setup. In the same test, the pressure drop vs. volumetric flow rate is measured and shown in Figure 1. As mentioned in Theory section, this curve is used to calculate the mass flow from the force measurements.

\section{Wind tunnel test}

The wind tunnel facility used is available at Volvo Cars. It is a closed loop wind tunnel powered by a $5 \mathrm{MW}$ fan with the capacity of reaching velocities up to $250 \mathrm{~km} / \mathrm{h}$ in the $27 \mathrm{~m}^{2}$ test section. The free-stream turbulence intensity is below $0.1 \%$ with less than 0.6 degrees deviation from main flow direction as has been shown by Sterneus et al. [10]. For the wind tunnel measurements, a PSI 8400 pressure system with ESP miniature electronic pressure scanners was used. The vehicle used in the wind tunnel measurements is a Volvo S60 production car and the test setup can be seen in Figure 6.

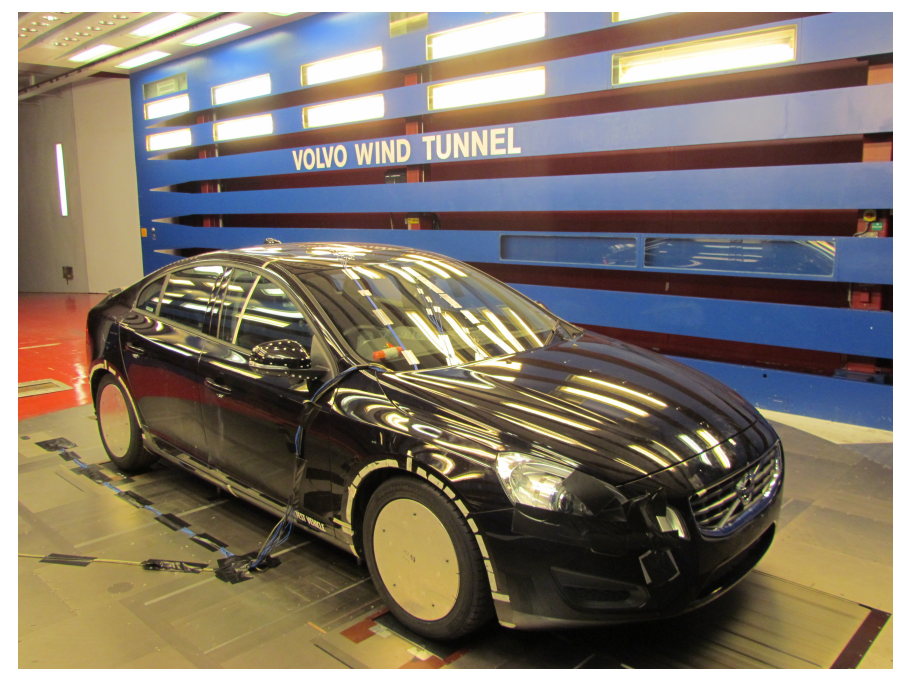

Figure 6: Schematic of the wind tunnel facility at Volvo Cars.

Some necessary modifications were made to the engine bay; only the combustion engine's heat exchanger was placed inside the vehicle's cooling package as to have only one pressure drop, and it was suspended on load-cells attached to the vehicle chassis. All components between the heat exchanger and the front bumper were removed; also all components normally connected to the heat exchanger's water tanks were removed, except for the fan shroud which was mounted to the vehicle chassis. The fan was removed and custom made aluminum ducts sealed the grill and spoiler inlets from the bumper to the heat exchanger core, thus shielding the heat exchanger's water tanks. All these modifications were made to ensure that the load-cells would measure only the force acting on the heat exchanger core. Figure 7 shows the heat exchanger mountings on both sides of the water tanks and their connection to the chassis. Complete 
system checks of the load-cells and the data acquisition system were performed using a digital dynamometer before placing the test object in the testing facility. Reliability, robustness, and repeatability of the system can then be ensured as it fully relies on electrical signals thus eliminating risks of leakages and clogging. The load-cells are calibrated before being placed in the vehicle and the system check confirms their functionality after comparison to the digital dynamometer readings.

The load-cells used in this test are ALEXEN cells with a measurement range up to $5 \mathrm{kN}$. For the sake of this investigation, a fine calibration test is performed showing a maximum deviation of $0.2 \mathrm{~N}$ throughout a $500 \mathrm{~N}$ test range. Although the load cells showed such high accuracy in the calibration rig, the full system functionality check, when mounted in the vehicle, showed a max deviation of $2 \mathrm{~N}$. This resulted in an overall uncertainty of about $5 \%$, at loads equivalent to testing at $80 \mathrm{~km} / \mathrm{h}$, and around $1 \%$, at loads equivalent to testing at $200 \mathrm{~km} / \mathrm{h}$. The main contributor to this uncertainty is the fact that the radiator is completely suspended on these two load cells. This not only adds a side load on the load cell, but also allows the core to slightly rotate under loading, thus resulting in some friction with the sealing ducts and little side forces. The repeatability of the test measurements has been evaluated for different configurations and has shown deviations of $1 \mathrm{~N}$. In order to avoid significant drifting in the readings, the load cells were connected for more than one and a half hour and the measurements were tared before the test began. The cell readings went back to zero whenever the radiator was not loaded, both in between configurations and at the end of the test.

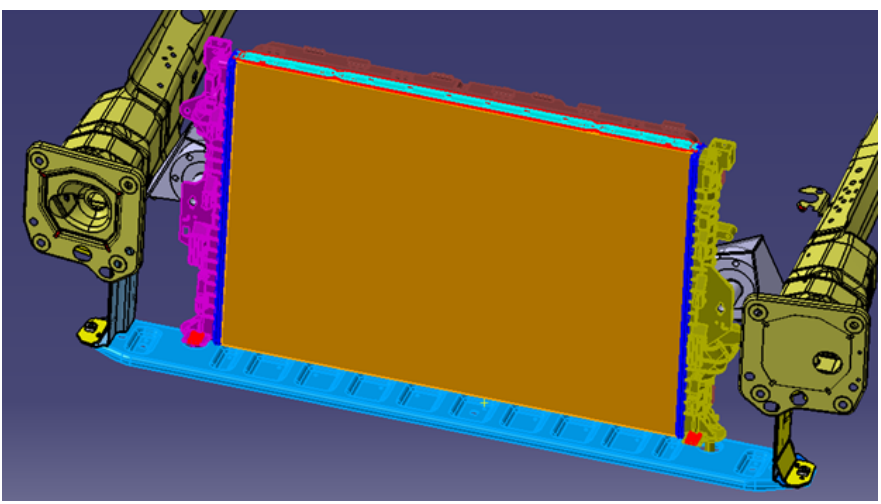

Figure 7: Heat exchanger mounting on load-cells (grey in color).

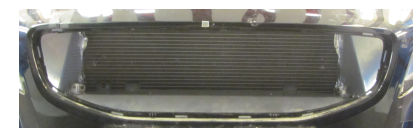

(a) Grill 1: Open grill

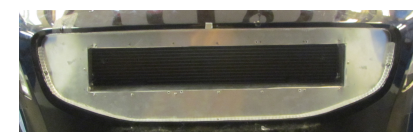

(c) Grill 3

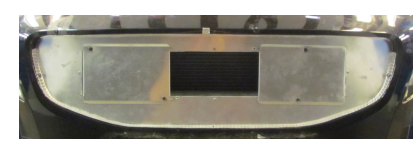

(e) Grill 5

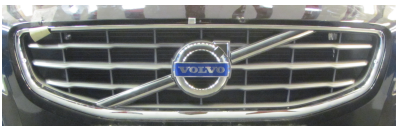

(b) Grill 2: Production grill

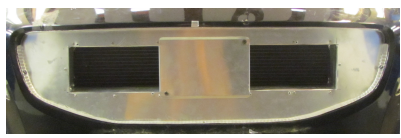

(d) Grill 4

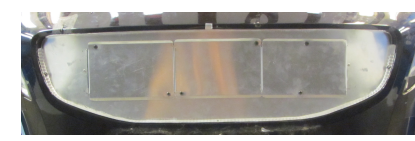

(f) Grill 6: Closed grill
Figure 8: The different grill designs sorted by blockage ratio from completely open to completely closed.

To evaluate the usefulness of the method in different flow fields, different grill configurations were tested in the wind tunnel, resulting in different mass flows through the heat exchanger. Figure 8 shows the various grill designs tested to introduce different blockage effects starting from completely open, lowest blockage in Figure 8a, and increasing up to fully closed, highest blockage in Figure $8 \mathrm{f}$. The real vehicle grill is also tested for benchmarking purposes. Different mass flows were investigated at different free stream velocities for each configuration, as the measurements were performed as a Reynolds number sweep of increasing free stream velocity from $80 \mathrm{~km} / \mathrm{h}$ to $200 \mathrm{~km} / \mathrm{h}$ in steps of $20 \mathrm{~km} / \mathrm{h}$ and at 0 degrees of yaw.

For all measurements, the spoiler opening in the lower part of the front bumper was left completely open as shown in Figure 9.

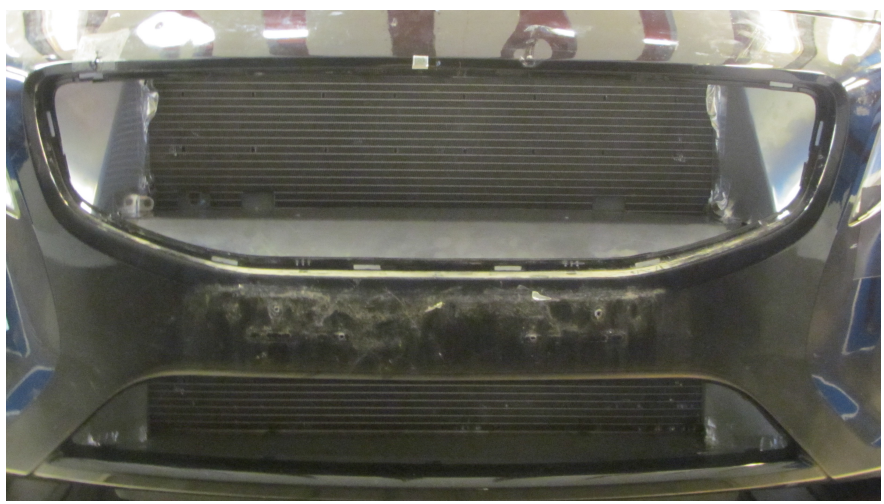

Figure 9: Grill 1 (Reference) configuration showing the aluminum ducts and the lower spoiler opening.

\section{Results and Discussion}

In this section, the force based method for air flow rate quantification through a heat exchanger is discussed. The heat exchanger is positioned in a passenger vehicle and necessary corrections are introduced together with an analysis of the uncertainty.

\section{Initial results}

Figure 10 shows the percentage difference between the average core velocity measured by the load-cells $v_{a v g_{-}} F$ and the corresponding velocity measured by conventional pressure probes $v_{a v g_{-} P}$ for different grill configurations. As expected, the force measurement tends to over-predict the pressure measurements, but for grills with low blockage, Grills 1,2, and 3, the mass flow rates from the load-cell measurements are within $\pm 4 \%$ of the pressure probes. However, as the blockage increases, Grill 4, 5, and 6, the over prediction increases due to the increase in inhomogeneity over the heat exchanger core.

Figure 11 shows the velocity distribution over the different grills along with the inhomogeneity value of each when tested at $200 \mathrm{~km} / \mathrm{h}$. The $6 \times 8$ grid of black dots represents the 48 pressure measurement points used to measure the local velocity at that specific location. Then the results are interpolated/extrapolated to a 470x672 grid using bilinear interpolation. It is the data from the refined grid which is used to calculate $v_{a v g} P$. 


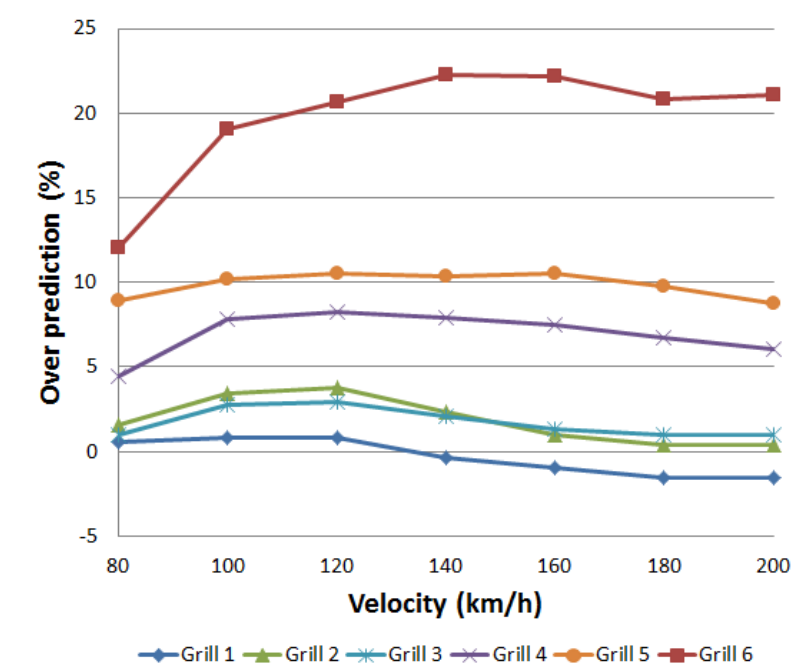

Figure 10: Percentage of over prediction comparing $v_{a v g_{-} F}$ to $v_{a v g_{-} P}$.

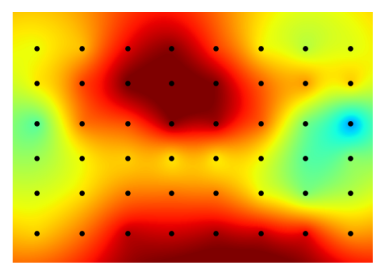

(a) Grill 1:20\%

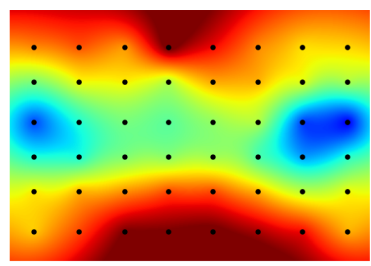

(c) Grill 3: 26\%

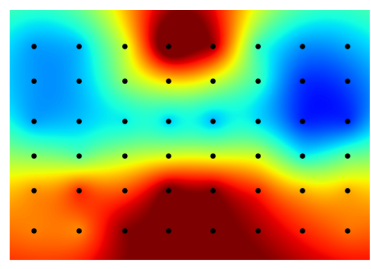

(e) Grill 5: 40\%

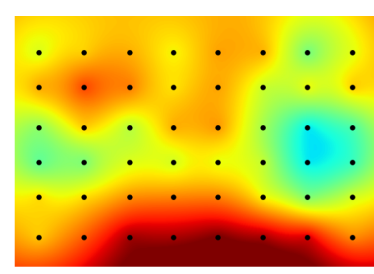

(b) Grill 2: 17\%

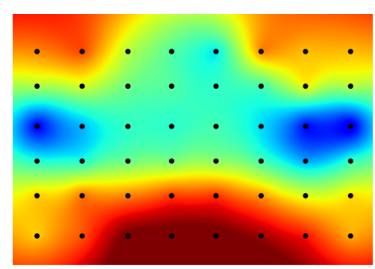

(d) Grill 4: $32 \%$

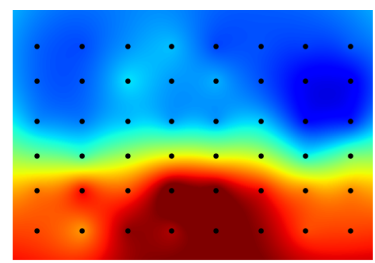

(f) Grill 6:55\%

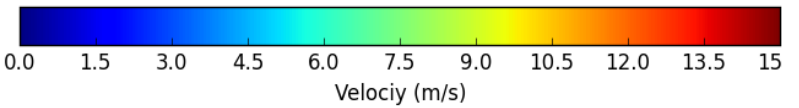

Figure 11: Velocity distribution through the heat exchanger core for the different grill configurations at $200 \mathrm{~km} / \mathrm{h}$ testing speed. Inhomogeneity values are also presented beneath each plot, respectively.

\section{Theoretical over prediction of average velocity}

It is possible to determine a "theoretical value" of the over predicted average velocity $\left(v_{\text {avg_Theory }}\right)$ entirely based on the velocity distribution measured by the 48 probes over the heat exchanger core, which in turn is calculated directly from the pressure measurements. This is done by converting the velocity distribution, for example presented in Figure 11, into a local pressure distribution, following Equation 6, from which a total force $\left(F_{t o t}\right)$ can be calculated by integrating over the the complete heat exchanger area. For comparison consistency, this total force is converted into vavg_Theory by Equation 7 .

$$
P_{\text {local }}=\left(\frac{1}{2} \rho C_{2} v_{\text {local }}^{2}+\frac{1}{\alpha} \mu v_{\text {local }}\right) \times \Delta x
$$

where $P_{\text {local }}$ is the equivalent net local pressure acting on the core and $v_{\text {local }}$ is the local velocity measured at that area section.

$$
v_{\text {avg_Theory }}=\frac{-\frac{1}{\alpha} \mu+\sqrt{\left(\frac{1}{\alpha} \mu\right)^{2}-4\left(\frac{1}{2} \rho C_{2}\right)\left(\frac{-F_{\text {tot }}}{V_{\text {core }}}\right)}}{2 \times \frac{1}{2} \rho C_{2}}
$$

Figure 12 shows the difference between $v_{a v g_{-} F}$ and $v_{\text {avg_Theory }}$ for the different grill configurations. Excluding Grill 6, the calculated mass flow through the heat exchanger core, from the load-cell measurements, seems to agree well with the theoretical value a force approach should measure, within a $\pm 5 \%$ uncertainty. This is a clear indication that the setup used to apply the load-cell method works well in measuring an average value of the force acting on the heat exchanger core. However,

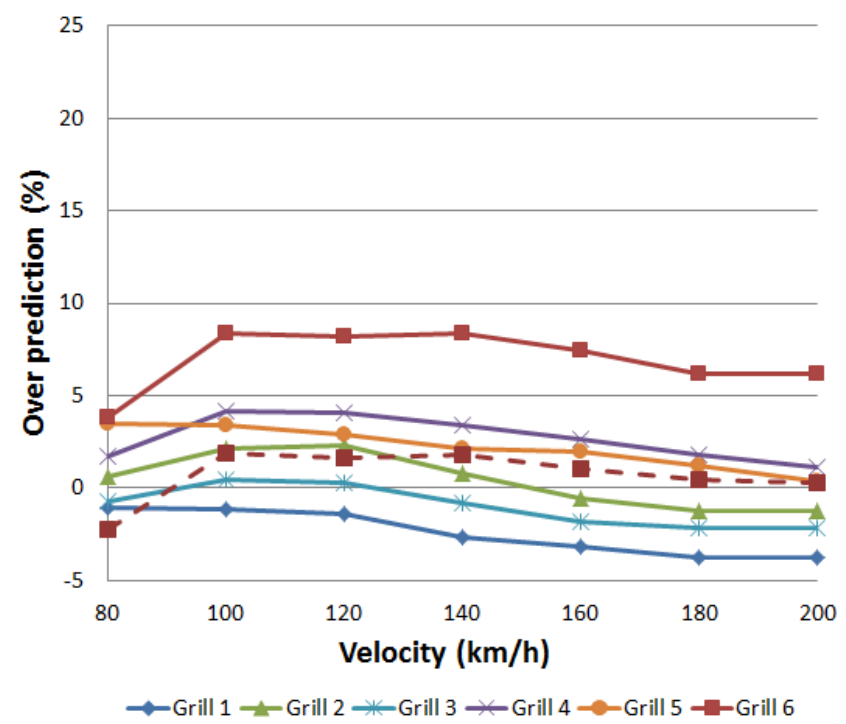

Figure 12: Percentage over prediction comparing $v_{a v g_{-} F}$ to $v_{a v g_{-} T h e o r y}$.

the percentage difference for Grill 6, the closed grill configuration, is high, so a closer look at the velocity distribution and integration is done. In Figure 11, the location of the pressure sensors are marked with black dots, and a key question in this context is how accurately the current measurement grid can capture the flow distribution, with an inhomogeneity as high as 55\%. A linear integration method has been used to integrate the 48 discrete velocity measurements over the radiator core. Looking at Figure 11f, a transition can be noted between rows 4 and 5 of the pressure probes, and this is an area where the transition from the low velocity, at the top of the radiator, to the high velocity, at the bottom occurs.

Although this transition seems to be smooth, this is an illusion since the linear interpolation smears out the effect and in reality the transition between rows 4 and 5 is quite abrupt. Tweaking of the gradient calculation shows that the effect of having a more steep transition at row 4 or at row 5 instead, can give a $13 \%$ difference in the flow rate through the heat exchanger. Making the same assessment for a heat exchanger with almost homogeneous flow, e.g. Grills 1 and 2, the corresponding difference is less than $2 \%$. This demonstrates how the overall uncertainty of the 48 probe measurement setup could be significantly large when measuring velocity distributions with high inhomogeneity. Due to the high gradient influence, a suggested correction for the transition effect of the Grill 6 is shown in Figure 12 as a dotted line, which now fits well with the other tested configurations. 


\section{Center of pressure correction}

After validating that the load-cell setup is working as expected and knowing that the force approach will over predict the mass flow due to the inhomogenous velocity distribution, a correction for $v_{a v g_{-} F}$ can be developed. This correction is based on the Center of Pressure offset $\left(\mathrm{CoP}_{\text {offset }}\right)$ from the geometrical center of the heat exchanger. This is done after the velocity distribution has been converted into a pressure distribution using Equation 6. A CoP offset for each measurement can be determined and illustrated in Figure 13 for the various grills at $200 \mathrm{~km} / \mathrm{h}$ testing speed. In the absence of the pressure distribution, the CoP $P_{\text {offset }}$ can be calculated when four load-cells are used to measure the overall force acting on the heat exchanger.

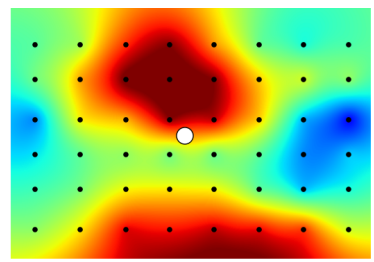

(a) Grill 1: $12 \mathrm{~mm}$

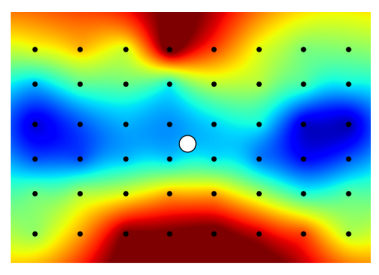

(c) Grill 3: $13 \mathrm{~mm}$

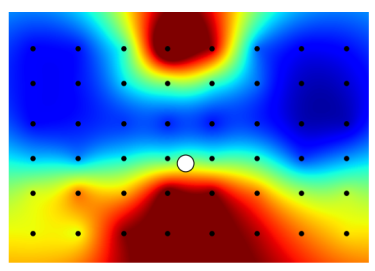

(e) Grill 5: $50 \mathrm{~mm}$

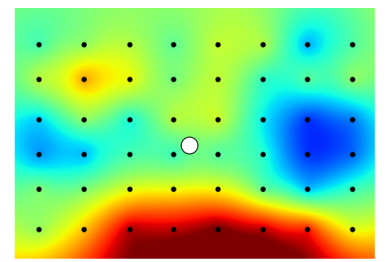

(b) Grill 2: $25 \mathrm{~mm}$

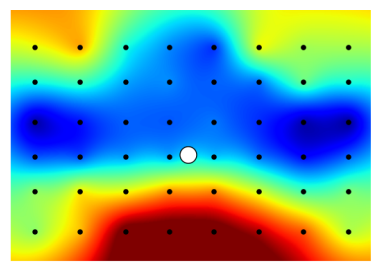

(d) Grill 4: $37 \mathrm{~mm}$

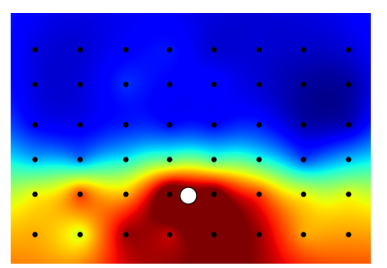

(f) Grill 6: $107 \mathrm{~mm}$

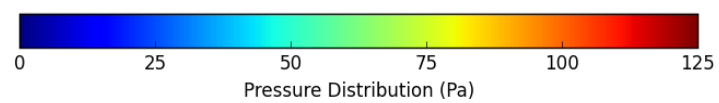

Figure 13: Pressure distribution over the heat exchanger core for the different grill configurations at $200 \mathrm{~km} / \mathrm{h}$ testing speed. The $C o P$ is presented as the white dot on each plot with the offset value from the radiator's geometrical center written beneath.

After the CoP $P_{\text {offset }}$ is computed, the percentage over prediction is also determined from the probe measurements as the percentage difference between $v_{a v g_{-} T h e o r y}$ and $v_{\text {avg_P }} P$. When the percentage over prediction is plotted against $C_{o} P_{\text {off set }}$ as shown in Figure 14, a second order polynomial correction curve, can be extracted. In order to get the correction curve as accurate as possible, around 200 data points where used to plot this curve which extends beyond the measurements reported in this paper and covers various grill configurations, free stream velocities, and flow alignment conditions.

Although the curve is computed from pressure measurements, it is possible to compute a similar curve in the plenum-to-plenum test rig where the CoP offset is measured using four load-cells and the percentage over prediction is the difference between $v_{a v g_{-} F}$ and the average velocity the test rig system measures. This allows the force

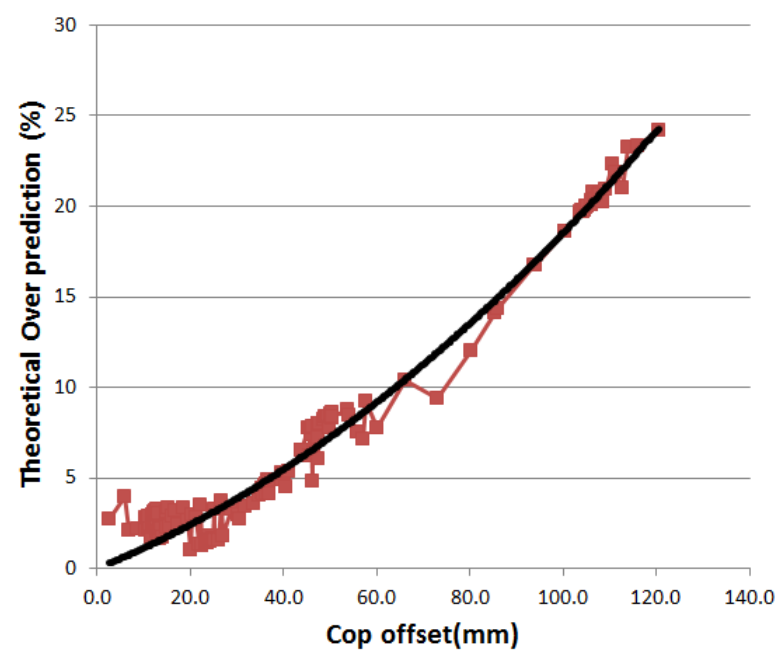

Figure 14: Percentage of theoretical over prediction comparing $v_{a v g}$ Theory to $v_{a v g_{-} P}$ plotted against $C o P$ offset from the geometric center of the heat exchanger. The curve fit represents the $\operatorname{CoP}$ correction curve.

method to be a standalone method for predicting mass flows which does not rely on any local pressure or velocity measurements.

The correction curve obtained can be used to correct $v_{a v g_{-} F}$ and obtain a $v_{\text {avg_Corr }}$. The difference between $v_{\text {avg_Corr }}$ and $v_{a v g_{-} P}$, presented in Figure 15, lies within a $\pm 5 \%$ margin for all configurations.

As shown in Figure 13, the $C o P$ can shift by more than $100 \mathrm{~mm}$ for Grill 6 which also has high inhomogeneity of $55 \%$, thus the correction will have a significant impact on the results, more than $20 \%$. However, for deviations below $30 \mathrm{~mm}$ and inhomogeneity values below $30 \%$, the correction curve offers little impact to the results; less than $4 \%$.

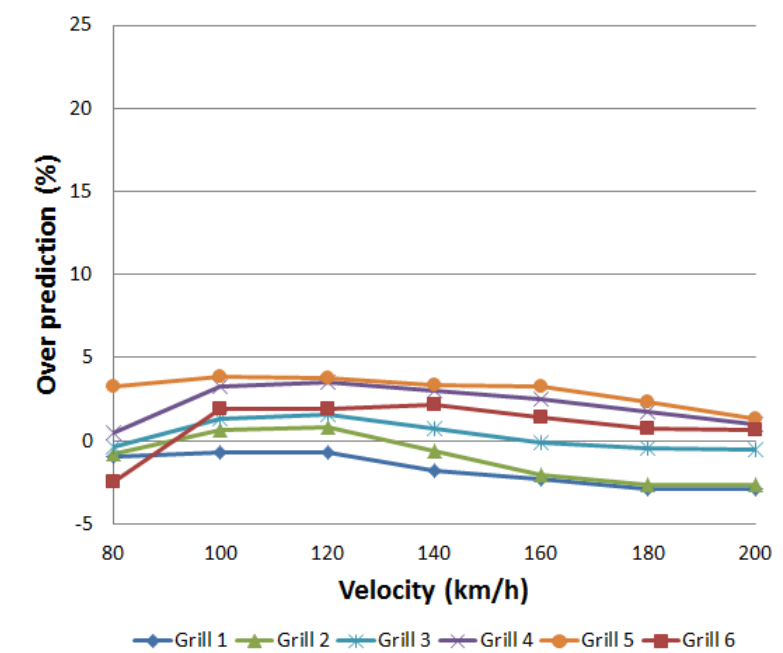

Figure 15: Percentage over prediction comparing $v_{a v g_{-} C o r r}$ to $v_{a v g_{-} P}$

\section{Method Uncertainties}

The traditional methods for measurements of the mass flow rate require a number of measuring points across the heat exchanger core, which need to be integrated over the total area to calculate the mass flow rate. Additional blockage from the measuring probes and integration of the discrete sensors are significant sources of error in this approach. Kuthada [11] has shown, through a CFD simulation investigation, that for a typical heat exchanger used in automotive applications with about 
$19 \%$ inhomogeneity, around 50 pressure measuring points are needed to enable a mass flow rate determination within a $2.5 \%$ discretization error margin. However, this error can still increase significantly with an increase in inhomogeneity as discussed in the theoretical over prediction section. The overall accuracy of the used micro-probes have shown to be within $2.2 \%$ error margin in the plenum-to-plenum test rig when blockage behind the heat exchanger is added to increase the inhomogeneity to $23 \%$. Similar results are reported by Kuthada [12].

The force approach does not suffer from the uncertainty introduced by discretization which itself is dependent on measurement grid density across the heat exchanger core. However it does introduce a different kind of uncertainty as it over predicts the mass flow due to inhomogeneous force distribution. This can be corrected for by using information of the center of pressure position and an additional curve extracted from the plenum-to-plenum test rig or similar facility.

\section{Conclusion}

A force based method, for measuring air flow rate through heat exchangers using load-cells, has been evaluated in a passenger car underhood and compared to a pressure based conventional method. From these measurements the following conclusions can been made:

- The force based method determines the air mass flow rate with comparable accuracy to that of a conventional pressure based method.

- Advantages of the force based method is that it is global and non-intrusive. It requires no integration over the radiator core area and can capture the effects of low velocities and recirculation.

- The load-cells are reliable, robust, easy to calibrate, and have good repeatability. The required data acquisition system is cheap and simple as compared to a pressure based method and full system checks can be performed outside of the testing facility.

- CFD computed forces can be directly compared to the force measurements.

The forced based method is fast, accurate and simple, making it well suited for modern optimization processes where short lead times are required.

\section{Future work}

Further investigations for quantifying the overall uncertainty of the force base method are yet to be performed. This requires empirically obtaining the $C o P$ correction curve from the fan test rig, where the installation of four force measuring devices would render the method completely standalone. The possibility of computing the correction curve from CFD simulations is also to be investigated.

Analysis into the uncertainty of the probe measurements for inhomogeneity conditions like Grill 6 would also help to understand the discrepancy between the force and pressure measurements for that configuration.

\section{References}

[1] Ng, E. Y., Johnson, P. W., Watkins, S., and Mole, L., "Use of Pressure-Based Technique for Evaluating the Aerodynamics of Vehicle Cooling Systems", SAE Technical Paper, (Detroit, Michigan, SAE International, 2002), DOI: 10.4271/2002-01-0712.
[2] Ruijsink, R, "The Use of the MicroProbe System in Cooling System Development", Third MIRA International Vehicle Aerodynamics Conference, (Rugby, UK, 2000), ISBN: 0952415623.

[3] Wille, S., Kuthada, T., Widdecke, N., Wiedemann, J., Maier, H., and Koller, A., "Integrated Numerical and Experimental Approach to Determine the Cooling Air Mass Flow in Different Vehicle Development Stages", SAE Int. J. Passeng. Cars - Mech. Syst. 3: 352-365, 2010, ISSN: 1946-4002, DOI: 10.4271/2010-01-0287.

[4] Foss, J. F., Schwannecke, J. K., Lawrenz, A. R., Mets, M. W., Treat, S. C., and Dusel, M. D., "The Thermal Transient Anemometer", Measurement Science and Technology 15: 2248-2255, 2004, Dor: 10.1088/0957-0233/15/11/010.

[5] Williams, J., "An Automotive Front-End Design Approach for Improved Aerodynamics and Cooling", SAE Technical Paper, (Detroit, Michigan, SAE International, 1985), DOI: $10.4271 / 850281$.

[6] Williams, J. and Vemaganti, G., "CFD Quality - A Calibration Study for Front-End Cooling Airflow", SAE Technical Paper, (Detroit, Michigan, SAE International, 1998), DoI: 10.4271/980039.

[7] Henriksson, L., "Performance of Compact Heat Exchanger in Non-Perpendicular Cooling Airflows", PhD thesis, Gothenburg, Sweden, 2015: 49, ISBN: 978-91-7597-164-3.

[8] Hucho, W. H., "Aerodynamics of Road Vehicles", Fourth, (Warrendale, USA, Society of Automotive Engineers, Inc, 1998): 559-561, ISBN: 0-7680-0029-7.

[9] Gullberg, P. V., "Optimisation of the Flow Process in Engine Bays- 3D Modelling of Cooling Airflow”, PhD thesis, Gothenburg, Sweden, 2011: 239-245, ISBN: 978-91-7385-559-4.

[10] Sterneus, J., Walker, T., and Bender, T., "Upgrade of the Volvo Cars Aerodynamic Wind Tunnel", SAE Technical Paper, (Detroit, Michigan, SAE International, 2007), DoI: 10.4271/2007-01-1043.

[11] Kuthada, T., "A review of Some Cooling Air Flow Measurement Techniques for Model Scale, Full Scale and CFD”, SAE Int. J. Passeng. Cars - Mech. Syst. 6: 88-96, 2013, ISSN: 1946-4002, DOI: $10.4271 / 2013-01-0598$.

[12] Kuthada, T., "Die Optimierung von Pkw Kuhlluftungssystemen unter dem Einfluss moderner Bodensimulationstechniken", PhD thesis, Stuttgart, Germany, 2006: 50-53, ISBN: 3-8169-2664-9.

\section{Contact Information}

Mr.Teddy Hobeika

Road Vehicle Aerodynamics Group

Division of Vehicle Engineering and Autonomous Systems

Department of Applied Mechanics

Chalmers University of Technology, Sweden

Tel. +46(0)700738996

teddy.hobeika@chalmers.se

\section{Acknowledgements}

The authors would like to thank Tim Walker and Dr. Christoffer Landström at Volvo Cars for their support and enlightening discussions as well as both Volvo Cars and Volvo GTT for granting access to their test facilities. Also a special thanks to Energimyndigheten (Swedish Energy Agency) for funding this research under project number 37195-1. 


\section{Nomenclature}

\begin{tabular}{|c|c|c|}
\hline Symbol & Units & Definition \\
\hline$v_{\text {avg_core }}$ & $m / s$ & Average velocity through radiator \\
\hline$\dot{m}_{\text {core }}$ & $\mathrm{kg} / \mathrm{s}$ & Mass flow through radiator \\
\hline$\dot{V}_{\text {core }}$ & $\mathrm{m}^{3} / \mathrm{s}$ & Volumetric flow through radiator \\
\hline$\rho_{\text {air }}$ & $\mathrm{kg} / \mathrm{m}^{3}$ & Air density \\
\hline$A_{\text {core }}$ & $m^{2}$ & Area of Radiator Core \\
\hline$F_{\text {core }}$ & $N$ & Force acting on the Core \\
\hline$\Delta P_{\text {core }}$ & $P a$ & Pressure drop through the radiator \\
\hline$C_{2}$ & $1 / m$ & Inertial resistance coefficient \\
\hline$\frac{1}{\alpha}$ & $1 / m^{2}$ & Viscous resistance coefficient \\
\hline$\mu$ & $\mathrm{kg} / \mathrm{m} . \mathrm{s}$ & Air dynamic viscosity \\
\hline$\Delta x$ & $m$ & Radiator core thickness \\
\hline$v_{a v g_{-} F}$ & $m / s$ & $\begin{array}{l}\text { Average radiator velocity calculated } \\
\text { from load cells }\end{array}$ \\
\hline$n$ & & Number of measurement points \\
\hline$\dot{m}_{\text {local_k }}$ & $\mathrm{kg} / \mathrm{s}$ & Mass flow rate through one area section \\
\hline$A_{\text {local_k }}$ & $m^{2}$ & Size of one area section \\
\hline$A_{\text {core }}$ & $m^{2}$ & $\begin{array}{l}\text { Size of the complete heat exchanger core } \\
\text { area }\end{array}$ \\
\hline$\dot{m}_{\text {core }}$ & $\mathrm{kg} / \mathrm{s}$ & $\begin{array}{l}\text { Total mass flow through the heat } \\
\text { exchanger }\end{array}$ \\
\hline$v_{a v g_{-} P}$ & $m / s$ & $\begin{array}{l}\text { Average radiator velocity calculated } \\
\text { from Pressure probes }\end{array}$ \\
\hline$F_{\text {local }}$ & $N$ & $\begin{array}{l}\text { Local force calculated from local } \\
\text { pressure probe }\end{array}$ \\
\hline$F_{\text {tot }}$ & $N$ & $\begin{array}{l}\text { Total Force calculated from pressure } \\
\text { probes }\end{array}$ \\
\hline$v_{\text {avg_Theory }}$ & $N$ & $\begin{array}{l}\text { Theoretical over-predicted velocity } \\
\text { calculated from } F_{\text {tot }}\end{array}$ \\
\hline$V_{\text {core }}$ & $m^{3}$ & Volume of Radiator Core \\
\hline CoP offset & $m m$ & $\begin{array}{l}\text { Center of pressure offset from geometric } \\
\text { center of the radiator }\end{array}$ \\
\hline
\end{tabular}

